\title{
Neural tube defects in Uganda: follow-up outcomes from a national referral hospital
}

\author{
Linda W. Xu, MD, ${ }^{1,2}$ Silvia D. Vaca, BS, ${ }^{1,2}$ Joy Q. He, AB,,2 Juliet Nalwanga, MBChB, MMed Surg, ${ }^{3}$ \\ Christine Muhumuza, MPH, ${ }^{4}$ Joel Kiryabwire, MBChB, MMed Surg, ${ }^{3}$ \\ Hussein Ssenyonjo, MBChB, MMed Surg, ${ }^{3}$ John Mukasa, MBChB, MMed Surg, ${ }^{3}$ \\ Michael Muhumuza, MBChB, MMed Surg, ${ }^{3}$ and Gerald Grant, MD ${ }^{1,2}$
}

\begin{abstract}
1Department of Neurosurgery, Stanford University; ${ }^{2}$ Stanford Center for Global Health Innovation, Palo Alto, California; ${ }^{3}$ Department of Neurosurgery, Mulago National Referral Hospital, Kampala; and ${ }^{4}$ School of Public Health, Makerere University, Kampala, Uganda
\end{abstract}

\begin{abstract}
OBJECTIVE Children with neural tube defects (NTDs) require timely surgical intervention coupled with long-term management by multiple highly trained specialty healthcare teams. In resource-limited settings, outcomes are greatly affected by the lack of coordinated care. The purpose of this study was to characterize outcomes of spina bifida patients treated at Mulago National Referral Hospital (MNRH) through follow-up phone surveys.

METHODS All children presenting to MNRH with NTDs between January 1, 2014, and August 31, 2015, were eligible for this study. For those with a documented telephone number, follow-up phone surveys were conducted with the children's caregivers to assess mortality, morbidity, follow-up healthcare, and access to medical resources.
\end{abstract}

RESULTS Of the 201 patients, the vast majority $(n=185,92 \%)$ were diagnosed with myelomeningocele. The median age at presentation was 6 days, the median length of stay was 20 days, and the median time to surgery was 10 days. Half of the patients had documented surgeries, with $5 \%$ receiving multiple procedures $(n=102,51 \%): 80$ defect closures $(40 \%), 32$ ventriculoperitoneal shunts (15\%), and 1 endoscopic third ventriculostomy $(0.5 \%)$. Phone surveys were completed for 53 patients with a median time to follow-up of 1.5 years. There were no statistically significant differences in demographics between the surveyed and nonrespondent groups. The 1-year mortality rate was $34 \%(n=18)$. At the time of survey, $91 \%$ of the survivors $(n=30)$ have received healthcare since their initial discharge from MNRH, with $67 \%(n=$ 22) returning to MNRH. Hydrocephalus was diagnosed in 29 patients (88\%). Caregivers reported physical deficits in $39 \%$ of patients $(n=13)$, clubfoot in $18 \%(n=6)$, and bowel or bladder incontinence in $12 \%(n=4)$. The surgical complication rate was 2.5\%. Glasgow Outcome Scale-Extended pediatric revision scores were correlated with upper good recovery in $58 \%(n=19)$ of patients, lower good recovery in $30 \%(n=10)$, and moderate disability in $12 \%$ of patients $(n=4)$. Only 5 patients $(15 \%)$ reported access to home health resources postdischarge.

CONCLUSIONS This study is the first to characterize the outcomes of children with NTDs that were treated at Uganda's national referral hospital. There is a great need for improved access to and coordination of care in antenatal, perioperative, and long-term settings to improve morbidity and mortality.

https://thejns.org/doi/abs/10.3171/2018.7.FOCUS18280

KEYWORDS follow-up; LMIC; low-middle-income countries; myelomeningocele; neural tube defects; Uganda

$\mathrm{S}$ PINA bifida or myelomeningocele describes a class of neural tube defects (NTDs) that are caused by incomplete neural tube closure during the 4th week of pregnancy and result in various levels of neurological deficit. Adequate folic acid consumption during early pregnancy prevents the occurrence of NTDs. However, because the neural tube closes by week 4 of fetal development, early access to antenatal care (ANC) is crucial in the prevention or early detection of NTDs. ${ }^{8}$ In Uganda, 4 routine ANC visits are recommended as part of the national clinical guidelines, with the first occurring between weeks 10 and 20 of gestation. ${ }^{11}$ Findings from the 2016

ABBREVIATIONS ANC = antenatal care; GOS-E Peds = pediatric revision of the Glasgow Outcome Scale-Extended; MNRH = Mulago National Referral Hospital; NTD = neural tube defect; SSA = sub-Saharan Africa; VP = ventriculoperitoneal.

SUBMITTED June 1, 2018. ACCEPTED July 12, 2018.

INCLUDE WHEN CITING DOI: 10.3171/2018.7.FOCUS18280. 
Uganda Demographic and Health Survey indicated that while $97 \%$ of Ugandan women accessed ANC at least once, only $60 \%$ completed the recommended 4 visits. The reasons for not attending visits included not knowing when to obtain ANC, believing ANC is unnecessary, and financial burden of transport. ${ }^{7}$ Because the neural tube closes by week 4 of fetal development, there is no clinical or educational infrastructure in place in Uganda for the prevention and/or early detection of NTDs. This likely contributes to the trend toward a higher incidence of NTDs in sub-Saharan Africa, although published data remain limited. ${ }^{4,15,18}$

The severity of NTDs depends on the level and degree of spinal cord exposure, with symptoms ranging from mild cosmetic symptoms, such as dimples or tufts of hair on the lower back in the case of spina bifida occulta, to severe paralysis, chronic infections, incontinence or retention, and paralysis in the case of rachischisis. Patients are also at increased risk for complications such as hydrocephalus, with the majority of patients with open spina bifida developing hydrocephalus that requires ventriculoperitoneal (VP) shunts. ${ }^{5,14}$ In an attempt to mitigate the complications associated with open spina bifida, the standard of care in upper-middle-income countries in the acute phase includes diagnosis in utero, cesarean section rather than vaginal birth to avoid infection, surgical closure of the open lesion within 24 hours, and continued monitoring for the development of hydrocephalus, with surgical intervention as needed. Moreover, due to the complexity of their diagnoses, patients in upper-middle-income countries are monitored by multiple highly trained specialty healthcare teams (e.g., neurosurgery, urology, orthopedics, pediatrics, physical therapy). In resource-limited settings, outcomes are greatly affected by the lack of coordinated care.

Outcomes research on pediatric spina bifida in sub-Saharan Africa (SSA) remains limited. A 2011 study in Eastern Uganda found the regional under-five mortality rate to be $37 \%$ for infants with treated spina bifida..$^{15}$ Of note, this rate was in a setting where medical care for spina bifida is relatively more accessible due to the presence of a regional pediatric hospital. Given that outcomes are known to greatly improve with initial survival and communitybased support, it is realistic to estimate that other districts of Uganda with even less access to community-based rehabilitation most likely have higher associated mortality.

In a 10-year survival study of Ugandan infants following myelomeningocele closure, Sims-Williams et al. found that most deaths were not directly related to myelomeningocele, but rather to infection and neglect. ${ }^{10}$ Furthermore, posthospitalization complications arise in SSA due to cultural beliefs or poverty, resulting in improper or altogether lack of treatment. ${ }^{3}$ Stigmas surrounding medical disabilities and birth defects further complicate spina bifida treatment and outcomes and severely impact the lives of patients and their caregivers, particularly those from lower socioeconomic backgrounds. ${ }^{6}, 13$ However, there is evidence that community-based support and follow-up for patients and their families significantly improve patient survival after surgical management. ${ }^{1}$ The outcomes of pediatric spina bifida in Uganda have yet to be elucidated at a national level.
In the present study, we sought to assess the mortality and quality of life of pediatric spina bifida patients presenting to Mulago National Referral Hospital (MNRH) in Uganda through a quick and affordable phone follow-up survey.

\section{Methods}

\section{Patient Population and Study Setting}

As the sole national referral hospital, MNRH serves as a tertiary referral hospital for the entire country, with most patients reporting low socioeconomic status. MNRH is located in Kampala, the capital of Uganda, in the central region. All patients presenting with spina bifida between January 1, 2014, and August 31, 2015, were entered into a database along with demographic information (age, sex, district of origin, telephone number), dates of admission, surgery, and discharge, diagnosis, treatment, and outcome.

\section{Ethics Approval}

Ethics approval was provided by the Stanford University IRB in the United States and the Makerere University IRB in Uganda.

\section{Data Collection}

Data collection was completed as described by $\mathrm{Xu}$ et al. ${ }^{17}$ Briefly, phone surveys were developed after reviewing the literature and survey designs, consulting a content expert, and performing a Ugandan collaborator review for adaptation to this setting. Surveys inquired about caregiver demographics, follow-up healthcare, morbidity and mortality, quality of life, and access to home health resources. Calls were conducted in the participant's language by Ugandan research staff.

\section{Statistical Analysis}

Data analysis was completed using Microsoft Excel 2013. Descriptive statistics were calculated for demographics, mortality, and follow-up healthcare (Tables 1-3). Chi-square statistics were calculated between surveyed and nonrespondent groups; $\mathrm{p}<0.05$ was considered significant. Functional outcomes were assessed using the Glasgow Outcome Scale-Extended pediatric version (GOS-E Peds). ${ }^{2}$

\section{Results}

\section{Inpatient Demographics}

During the study period, 201 spina bifida patients (77 females, $38 \%$ ) presented to MNRH with a median age of 6 days (Table 1). The median length of stay was 20 days. Ninety-two percent of patients $(n=185)$ had a myelomeningocele, with 87 patients (43\%) presenting with concurrent myelomeningocele and hydrocephalus; 9 patients presented with an encephalocele (4\%), 3 with cranium bifidum (1\%), 2 with spina bifida occulta (1\%), and 2 with anencephaly (1\%).

One-hundred six patients (53\%) were born at term, 2 were born prematurely (1\%), and 93 (46\%) did not have a documented gestation age. Similarly, 96 patients were 
TABLE 1. Inpatient demographics

\begin{tabular}{|c|c|c|}
\hline & Value* & Percentage \\
\hline \multicolumn{3}{|l|}{ Patient demographics } \\
\hline No. of patients treated & 201 & \\
\hline Female & 77 & $38 \%$ \\
\hline Male & 124 & $62 \%$ \\
\hline Median age, days & 6 & \\
\hline Discharged w/ documented phone no. & 78 & \\
\hline Median length of stay, days & 20 & \\
\hline \multicolumn{3}{|l|}{ Diagnosis category } \\
\hline MMC & 185 & $92 \%$ \\
\hline MMC \& hydrocephalus $†$ & 87 & $43 \%$ \\
\hline Encephalocele & 9 & $4 \%$ \\
\hline Cranium bifidum & 3 & $1.5 \%$ \\
\hline Spina bifida occulta & 2 & $1 \%$ \\
\hline Anencephaly & 2 & $1 \%$ \\
\hline \multicolumn{3}{|l|}{ Gestation age } \\
\hline Term & 106 & $53 \%$ \\
\hline Premature & 2 & $1 \%$ \\
\hline Not specified & 93 & $46 \%$ \\
\hline \multicolumn{3}{|l|}{ Mode of delivery } \\
\hline Spontaneous vaginal delivery & 96 & $48 \%$ \\
\hline Cesarean section & 8 & $4 \%$ \\
\hline Not specified & 97 & $48 \%$ \\
\hline \multicolumn{3}{|l|}{ Treatment‡ } \\
\hline Surgical intervention & 102 & $51 \%$ \\
\hline Defect closuref & 80 & $40 \%$ \\
\hline VP shunt & 32 & $15 \%$ \\
\hline ETV & 1 & $0.5 \%$ \\
\hline Not specified & 99 & $49 \%$ \\
\hline \multicolumn{3}{|l|}{ Outcome } \\
\hline Died & 4 & $2 \%$ \\
\hline Discharged & 103 & $51 \%$ \\
\hline Unknown & 94 & $47 \%$ \\
\hline
\end{tabular}

ETV = endoscopic third ventriculostomy; MMC = myelomeningocele.

* Values are presented as the number of patients unless specified otherwise.

$\dagger$ A subset of patients with myelomeningocele was concurrently diagnosed with hydrocephalus.

$\ddagger$ A subset of patients underwent both defect closure and VP shunt placement during hospitalization (11, 5\%).

born via spontaneous vaginal delivery (48\%) and 8 via cesarean section (4\%); the delivery method was not specified for 97 children (48\%).

A total of 113 procedures were performed in 102 patients, accounting for over half of the patients admitted for spina bifida $(\mathrm{n}=102,51 \%)$ : 80 defect closures $(40 \%), 32$ ventriculoperitoneal (VP) shunts (15\%), and 1 endoscopic third ventriculostomy $(0.5 \%)$. Time-to-surgery data were available for 30 patients (15\%), with a median time of 10 days to surgery (range 1-33 days).

Four (2\%) patients died in the hospital, $103(51 \%)$ were discharged, and 94 were not specified (47\%). Of those who survived their hospital stay, 78 had a phone number on file.
TABLE 2. Patient demographics at follow-up

\begin{tabular}{|c|c|c|}
\hline & Value* $^{*}$ & Percentage \\
\hline \multicolumn{3}{|l|}{ Patient demographics } \\
\hline No. of patients w/ survey results & 53 & \\
\hline Female & 17 & $32 \%$ \\
\hline Male & 36 & $68 \%$ \\
\hline Median age, yrs & 1.76 & \\
\hline Median time to follow-up, yrs & 1.51 & \\
\hline \multicolumn{3}{|l|}{ Diagnosis category } \\
\hline Myelomeningocele (MM) & 39 & $74 \%$ \\
\hline MM \& hydrocephalus & 10 & $19 \%$ \\
\hline Encephalocele & 3 & $6 \%$ \\
\hline Cranium bifidum & 0 & $0 \%$ \\
\hline Spina bifida occulta & 1 & $2 \%$ \\
\hline Anencephaly & 0 & $0 \%$ \\
\hline \multicolumn{3}{|l|}{ Region of residence } \\
\hline Central & 38 & $72 \%$ \\
\hline Western & 13 & $25 \%$ \\
\hline Eastern & 1 & $2 \%$ \\
\hline Northern & 1 & $2 \%$ \\
\hline \multicolumn{3}{|l|}{ Caregiver religion } \\
\hline Christian & 8 & $15 \%$ \\
\hline Muslim & 45 & $85 \%$ \\
\hline \multicolumn{3}{|l|}{ Caregiver education } \\
\hline None & 2 & $4 \%$ \\
\hline Primary & 18 & $34 \%$ \\
\hline Secondary & 27 & $51 \%$ \\
\hline Diploma/certificate & 6 & $11 \%$ \\
\hline \multicolumn{3}{|l|}{ Caregiver occupation } \\
\hline Business & 21 & $40 \%$ \\
\hline Farmer & 16 & $30 \%$ \\
\hline Salaried worker & 7 & $13 \%$ \\
\hline Skilled worker & 1 & $2 \%$ \\
\hline Unemployed & 8 & $15 \%$ \\
\hline
\end{tabular}

* Values are presented as the number of patients unless stated otherwise.

TABLE 3. Mortality

\begin{tabular}{lcc}
\hline & Value $^{*}$ & Percentage \\
\hline Follow-up mortality & & \\
\hline Overall mortality & 20 & $38 \%$ \\
\hline 30-day mortality & 12 & $23 \%$ \\
\hline 1-yr mortality & 18 & $34 \%$ \\
\hline Median discharge to death, days & 20 & \\
\hline Cause of death & & \\
\hline Spina bifida complications & 14 & $70 \%$ \\
\hline Surgical site infection & 3 & $15 \%$ \\
\hline Other infection & 2 & $10 \%$ \\
\hline Intestinal complications & 1 & $5 \%$ \\
\hline
\end{tabular}

* Values are presented as the number of patients unless stated otherwise. 


\section{Follow-Up Demographics}

A total of 53 patients (17 female, 32\%) were surveyed with a median time to follow-up of 1.51 years (Table 2). Of these patients, 49 (92\%) were diagnosed with a myelomeningocele, of whom 10 (19\%) had concurrent myelomeningocele and hydrocephalus. Three patients $(6 \%)$ were diagnosed with an encephalocele, and one (2\%) with spina bifida occulta. Three-quarters of patients $(n=40)$ had surgical intervention: 35 (66\%) defect closures and 11 (21\%) VP shunts, with 6 (11\%) of those patients undergoing both defect closure and VP shunt placement.

Most patients $(72 \%, \mathrm{n}=38)$ resided in the central region, where MNRH is located, with $25 \%(\mathrm{n}=13)$ in the western region and $2 \%$ each in the eastern and northern regions $(\mathrm{n}=1$ each). The mother was the primary caregiver for $92 \%$ of patients $(n=49)$, followed by the father for $8 \%$ of patients $(n=4)$. Eighty-five percent $(n=45)$ of caregivers had either primary or secondary education, $11 \%$ ( $\mathrm{n}=$ 6) had a diploma or certificate, and $4 \%(n=2)$ had no formal education. The most common caregiver occupations were business $(40 \%, \mathrm{n}=21)$ and farming $(30 \%, \mathrm{n}=16)$, followed by salaried work (13\%, $\mathrm{n}=7)$ and skilled work $(2 \%, \mathrm{n}=1) ; 15 \%$ of caregivers $(\mathrm{n}=8)$ were unemployed. There were no statistically significant differences between the surveyed and nonrespondent group demographics.

\section{Mortality}

At follow-up, 20 (38\%) patients had died; the 30-day mortality rate was $23 \%(\mathrm{n}=12)$, and the 1-year mortality rate was $34 \%(n=18$; Table 3$)$. The median time from discharge to death was 20 days. The leading cause of death reported was complications of the disease or surgical intervention $(\mathrm{n}=17,85 \%)$, with surgical site infections reported in 3 patients. Two patients died of other infections, and 1 died of intestinal complications.

There was no statistically significant difference in mortality between patients who underwent surgery $(\mathrm{n}=$ $40 ; 38 \%$ mortality) and those who did not $(\mathrm{n}=13 ; 38 \%$ mortality) $(p=0.95)$. Similarly, there was no statistically significant difference in mortality between females $(\mathrm{n}=$ $17,53 \%$ mortality) and males ( $\mathrm{n}=36 ; 31 \%$ mortality) $(\mathrm{p}$ $=0.12$ ).

\section{Follow-Up Healthcare}

Of survivors, $91 \%(\mathrm{n}=30)$ have received healthcare since their initial discharge from MNRH: 27 caregivers $(82 \%)$ reported a clinic visit, and $3(9 \%)$ patients were readmitted (Table 4). Two of the readmitted patients received a VP shunt, and 1 (originally managed nonoperatively) underwent a myelomeningocele closure at a regional hospital. Three patients (9\%) did not receive healthcare postdischarge. Two-thirds of patients $(n=22)$ returned to MNRH for their care, and $82 \%(n=27)$ reported spina bifida as the reason for their visit. Caregivers of 2 patients $(6 \%)$ cited hydrocephalus and 1 cited $(3 \%)$ malaria as the reason for their visit.

\section{Quality of Life Measures}

At the time of follow-up, the average patient age was 1.76 years (range 1.19-3.23 years). Caregivers reported
TABLE 4. Follow-up healthcare

\begin{tabular}{lrc}
\hline & No. of Patients & Percentage \\
\hline Follow-up healthcare & & \\
\hline Received healthcare & 30 & $91 \%$ \\
\hline Hospital admission & 3 & $9 \%$ \\
\hline Clinic visit & 27 & $82 \%$ \\
\hline Did not receive healthcare & 3 & $9 \%$ \\
\hline Returned to MNRH & 22 & $67 \%$ \\
\hline Reason for care & & \\
\hline Spina bifida & 27 & $82 \%$ \\
\hline Hydrocephalus & 2 & $6 \%$ \\
\hline Malaria & 1 & $3 \%$ \\
\hline
\end{tabular}

that $13(39 \%)$ patients developed a physical movement problem. Fourteen (42\%) patients were able to follow commands, and $30(91 \%)$ could speak. With respect to psychosocial function, all patients $(n=33)$ were reportedly friendly, 30 (91\%) played every day, $27(82 \%)$ behaved well with parents, and 15 (45\%) behaved well with siblings. GOS-E Peds scores were correlated with upper good recovery in $58 \%(\mathrm{n}=19)$ of patients, lower good recovery in $30 \%(\mathrm{n}=10)$, upper moderate disability in $9 \%(\mathrm{n}=3)$, and lower moderate disability in 3\% $(\mathrm{n}=1)$ of patients (Tables 4 and 5).

\section{Associated Conditions and Complications}

Hydrocephalus was diagnosed in 29 (88\%) patients, with 8 (24\%) patients reporting increased head circumference at follow-up (Table 5). Six (18\%) patients were found to have clubfoot, and scoliosis was reported in 1 (3\%) patient. Bowel or bladder incontinence was present in 4 (12\%) patients. Of the 40 patients who underwent surgery, 1 patient developed wound dehiscence and a CSF leak, resulting in a surgical complication rate of $2.5 \%$.

\section{Access to Home Health Resources}

Of the 33 survivors, 5 patients (15\%) reported access to home health resources postdischarge. Four patients received clubfoot braces: 3 at MNRH and 1 at Kalangala Medical Center. The patient who underwent surgery at the Mbale CURE regional hospital received monthly home visits.

\section{Discussion}

Our findings show that the availability of medical resources and documentation for spina bifida patients in Kampala, Uganda, is very limited, and that, unsurprisingly, the lack of resources and infrastructure translates to poor patient outcomes. Nearly half of our spina bifida patients were delivered vaginally, demonstrating a lack of antenatal care and counseling that these children should be delivered via cesarean section. The 1-year mortality rate for spina bifida patients at MNRH was $34 \%$. This is moderately higher than that reported in similar studies, e.g., $29 \%$ in rural northern Tanzania and $27 \%$ in southern Nigeria, but far greater than that of high-income countries. 
TABLE 5. Quality of life measures and associated conditions

\begin{tabular}{lc}
\hline \multicolumn{2}{l}{ Percentage of Patients } \\
\hline Psychosocial function \\
\hline Friendly \\
\hline Plays every day \\
\hline Behaves w/ parents & $100 \%$ \\
\hline Behaves w/ siblings & $91 \%$ \\
\hline Neurological function & $82 \%$ \\
\hline Physical movement deficit & $45 \%$ \\
\hline Can follow commands & \\
\hline Can say words & $39 \%$ \\
\hline Associated conditions & $42 \%$ \\
\hline Hydrocephalus diagnosis & $91 \%$ \\
\hline Increased head circumference & $88 \%$ \\
\hline Clubfoot & $24 \%$ \\
\hline Bowel or bladder incontinence & $18 \%$ \\
\hline CSF leak & $12 \%$ \\
\hline Wound dehiscence & $6 \%$ \\
\hline Seizures & $6 \%$ \\
\hline Scoliosis & $6 \%$ \\
\hline
\end{tabular}

For comparison, a 2012 study in the United States reported a 1-year mortality rate of $6.4 \%$ in infants born with spina bifida between 1998 and 2002. ${ }^{9,12,16}$ Interestingly, the mortality rate in the MNRH cohort is nearly 2-fold (34\% vs $19 \%$, respectively) that reported in recent studies from a regional pediatric neurosurgical center in Eastern Uganda where patients usually undergo surgery within 48 hours, are closely monitored for hydrocephalus, and have access to routine follow-up healthcare..$^{10}$ The marked difference in mortality between these 2 cohorts highlights the opportunity to better outcomes at a national level by improving coordination of care and timely access to surgery.

The leading cause of death in spina bifida patients at MNRH was reported to be spina bifida complications or surgical site infections $(85 \%)$. Forty-three percent of patients at hospital admission were noted to have hydrocephalus, but at follow-up the eventual percentage of associated hydrocephalus was $88 \%$. As only $15 \%$ received shunts at MNRH prior to discharge, with little clinical care received after discharge, compared to $97 \%$ of patients in the aforementioned Eastern Uganda study who underwent surgery for hydrocephalus, it is possible that the high mortality could be related to undiagnosed hydrocephalus. ${ }^{10}$ For patients who did survive, although $39 \%$ of caretakers reported physical disabilities, only 4 patients total received assistive braces and only $15 \%$ had access to home health resources after discharge. This disparity emphasizes the dramatic unmet need for this population of patients.

GOS-E Peds scores fell in a bimodal distribution, with the majority of patients either dead at the time of followup or having mild disability and good recovery, with only $12 \%$ of caregivers reporting moderate disability and none reporting severe disability. This distribution suggests that within 1 year of discharge, patients either progress to death or recover many functions, with few patients able to continue living with moderate to severe disability in the community.

While it is encouraging that the majority of caregivers reported normal cognitive and social development in patient survivors, one of the key limitations to our study is that it is dependent on anecdotal reports of subjective interpretations by caregivers. Therefore, we were unable to obtain reliable, standardized neurological assessments of patients during follow-up. Moreover, due to the self-reported nature of the questionnaire, we were unable to reliably assess for patient neglect by the family or caregiver.

Many patients were discharged against medical advice and prior to receiving treatment. In our study, $48 \%$ had no documented disposition, either discharge or death. The lack of documented disposition mostly reflects the frequency of patients leaving the hospital against medical advice. Several factors can contribute to this phenomenon. One factor is pressure on mothers to return to their homes and families as they are typically the primary caretaker for other members of the family. Another significant factor can be financial limitation. Although evaluation and admission to the hospital is free, before surgery can be undertaken, the families had to gather money to pay for laboratory tests, CT scans, and purchase shunts, which may have become impossible for some families. These factors are further exacerbated by extraordinarily long wait times for surgery. Patients in this cohort waited a median time of 10 days to surgery, with some patients waiting over a month for surgical intervention. This delay likely contributed to the number of family members that chose to take their children home rather than to continue to wait for intervention. Since documentation was inconsistent, we cannot be certain that all $48 \%$ without documentation reflected families that left without medical treatment. Our results found that medical records at MNRH were not consistently implemented or maintained. These alarming results accentuate the need for proper medical record infrastructure as the basis for delivering care to low-middleincome countries. Proper training of medical professionals is important, but without transparent documentation of patient data and follow-up care, it is exceedingly difficult to identify problem areas to raise the standard of care meaningfully and consistently.

\section{Conclusions}

Patients with spina bifida in Uganda experience a lack of coordinated care prior to, during, and after birth, lack of timely access to surgery and longitudinal medical resources after discharge, and inconsistent medical documentation throughout. This shortfall culminates in a higher 1-year mortality compared with upper-middle-income countries and demonstrates the greater need for improved care in antenatal, perinatal, and long-term settings.

\section{Acknowledgments}

We acknowledge Doreen Nankunda and Evarest Ahaisibwe for their assistance in data collection.

Funding was provided by the Stanford Medical Scholars Fellowship Program. 


\section{References}

1. Bannink F, Stroeken K, Idro R, van Hove G: Community knowledge, beliefs, attitudes, and practices towards children with spina bifida and hydrocephalus in Uganda. Int J Disabil Dev Educ 62:182-201, 2015

2. Beers SR, Wisniewski SR, Garcia-Filion P, Tian Y, Hahner $\mathrm{T}$, Berger RP, et al: Validity of a pediatric version of the Glasgow Outcome Scale-Extended. J Neurotrauma 29:1126-1139, 2012

3. Djientcheu VDP , Njamnshi AK, Wonkam A, Njiki J, Guemse M, Mbu R, et al: Management of neural tube defects in a Sub-Saharan African country: the situation in Yaounde, Cameroon. J Neurol Sci 275:29-32, 2008

4. Eke CB, Uche EO, Chinawa JM, Obi IE, Obu HA, Ibekwe $\mathrm{RC}$ : Epidemiology of congenital anomalies of the central nervous system in children in Enugu, Nigeria: a retrospective study. Ann Afr Med 15:126-132, 2016

5. Elgamal EA: Natural history of hydrocephalus in children with spinal open neural tube defect. Surg Neurol Int 3:112, 2012

6. Holmbeck GN, Devine KA: Psychosocial and family functioning in spina bifida. Dev Disabil Res Rev 16:40-46, 2010

7. Kisuule I, Kaye DK, Najjuka F, Ssematimba SK, Arinda A, Nakitende G, et al: Timing and reasons for coming late for the first antenatal care visit by pregnant women at Mulago hospital, Kampala Uganda. BMC Pregnancy Childbirth 13:121, 2013

8. Northrup H, Volcik KA: Spina bifida and other neural tube defects. Curr Probl Pediatr 30:313-332, 2000

9. Shin M, Kucik JE, Siffel C, Lu C, Shaw GM, Canfield MA, et al: Improved survival among children with spina bifida in the United States. J Pediatr 161:1132-1137, 2012

10. Sims-Williams HJ, Sims-Williams HP, Kabachelor EM, Fotheringham J, Warf BC: Ten-year survival of Ugandan infants after myelomeningocele closure. J Neurosurg Pediatr 19:70-76, 2017

11. Uganda Bureau of Statistics, ICF: Uganda Demographic and Health Survey 2016: Key Indicators Report. Kampala, Uganda: UBOS, and Rockville, Maryland, 2017 (https:// www.ubos.org/onlinefiles/uploads/ubos/pdf\%20documents/ Uganda_DHS_2016_KIR.pdf) [Accessed August 8, 2018]

12. Ugwu RO, Eneh AU, Oruamabo RS: Neural tube defects in a university teaching hospital in southern Nigeria: trends and outcome. Niger J Med 16:368-371, 2007

13. van't Veer T, Meester H, Poenaru D, Kogei A, Augenstein K,
Bransford R: Quality of life for families with spina bifida in Kenya. Trop Doct 38:160-162, 2008

14. Warf BC: Hydrocephalus associated with neural tube defects: characteristics, management, and outcome in sub-Saharan Africa. Childs Nerv Syst 27:1589-1594, 2011

15. Warf BC, Wright EJ, Kulkarni AV: Factors affecting survival of infants with myelomeningocele in southeastern Uganda. J Neurosurg Pediatr 7:127-133, 2011

16. Winkler AS, Tluway A, Slottje D, Schmutzhard E, Härtl R: The pattern of neurosurgical disorders in rural northern Tanzania: a prospective hospital-based study. World Neurosurg 73:264-269, 2010

17. Xu LW, Vaca SD, Nalwanga J, Muhumuza C, Vail D, Lerman BJ, et al: Life after the neurosurgical ward in Sub-Saharan Africa: neurosurgical treatment and outpatient outcomes in Uganda. World Neurosurg 113:e153-e160, 2018

18. Zaganjor I, Sekkarie A, Tsang BL, Williams J, Razzaghi H, Mulinare J, et al: Describing the prevalence of neural tube defects worldwide: a systematic literature review. PLoS One 11:e0151586, 2016

\section{Disclosures}

The authors report no conflict of interest concerning the materials or methods used in this study or the findings specified in this paper.

\section{Author Contributions}

Conception and design: Grant, Xu, Vaca, Nalwanga, C Muhumuza, Kiryabwire, Ssenyonjo, Mukasa, M Muhumuza. Acquisition of data: Grant, Vaca, Nalwanga, C Muhumuza, Kiryabwire, Ssenyonjo, Mukasa, M Muhumuza. Analysis and interpretation of data: Xu, Vaca, He. Drafting the article: Xu, Vaca, He. Critically revising the article: Grant, Xu, Nalwanga, C Muhumuza, Kiryabwire, Ssenyonjo, Mukasa, M Muhumuza. Reviewed submitted version of manuscript: all authors. Approved the final version of the manuscript on behalf of all authors: Grant. Administrative/techni$\mathrm{cal} /$ material support: C Muhumuza. Study supervision: Grant, Xu.

\section{Correspondence}

Gerald Grant: Stanford University, Stanford, CA. ggrant2@ stanford.edu. 